\title{
Mitotic rate is a more reliable unfavorable prognosticator than ulceration for early cutaneous melanoma: A 5-year survival analysis
}

\author{
PIOTR DONIZY ${ }^{1}$, MACIEJ KACZOROWSKI ${ }^{1}$, MAREK LESKIEWICZ ${ }^{2}$, MARCIN ZIETEK ${ }^{3}$, \\ MALGORZATA PIENIAZEK $^{4}$, CYPRIAN KOZYRA ${ }^{2}$, AGNIESZKA HALON $^{1}$ and RAFAL MATKOWSKI ${ }^{3,4}$ \\ ${ }^{1}$ Department of Pathomorphology and Oncological Cytology, Wrocław Medical University, 50-556 Wrocław; \\ ${ }^{2}$ Department of Statistics, Wrocław University of Economics, 53-345 Wrocław; ${ }^{3}$ Lower Silesian Oncology Centre, \\ 53-413 Wrocław; ${ }^{4}$ Department of Oncology and Division of Surgical Oncology, \\ Wrocław Medical University, 53-413 Wrocław, Poland
}

Received July 2, 2014; Accepted September 9, 2014

DOI: 10.3892/or.2014.3531

\begin{abstract}
The presence of ulceration has been considered as one of the most important primary tumor characteristics of cutaneous malignant melanoma (CMM) for predicting patient outcome. Yet recently, scientific attention has been drawn towards another microscopic feature of primary tumors, the mitotic rate (MR). The present study aimed to examine the relationship between the presence of ulceration and the mitotic rate and clinicopathological characteristics and melanoma patient survival, and to discuss the results in the context of AJCC melanoma staging recommendations. Tissue samples were obtained from 104 patients treated for CMM. In classical $H \& E$ staining, the mitotic rate and the presence of ulceration were evaluated. Non-mitogenic tumors were defined as having 0 mitoses $/ \mathrm{mm}^{2}$, low mitogenic potential, 1-2 mitoses $/ \mathrm{mm}^{2}$ and highly mitogenic tumors, $\geq 3$ mitoses $/ \mathrm{mm}^{2}$. In the entire group of 104 patients, a high mitotic rate (hMR) and ulceration were highly negative prognostic factors, and indicated considerably shorter overall survival, cancer-specific overall survival and disease-free survival. Notably, hMR appeared to have a statistically significant negative impact on survival in early melanomas in both the pT1 $(\mathrm{P}=0.001)$ and $\mathrm{pT} 2$ subgroups $(\mathrm{P}=0.006)$. Kaplan-Meier analysis of the remaining subsets (pT3 and pT4) did not reveal any important differences in the 5-year survival with regard to MR values. The presence of ulceration also had a prognostic significance for early melanomas, but only for pT1 tumors $(\mathrm{P}=0.05)$. Multivariate analysis confirmed that hMR was strongly associated with an unfavorable prognosis. Ulceration had no prognostic signifi-
\end{abstract}

Correspondence to: Dr Piotr Donizy, Department of Pathomorphology and Oncological Cytology, Wrocław Medical University, 213 ul. Borowska, 50-556 Wrocław, Poland

E-mail: piotrdonizy@wp.pl

Key words: mitotic rate, ulceration, melanoma, prognosis cance in the Cox proportional hazards model. Considering the biology of melanoma, hMR seems to be a more reliable parameter than the presence of ulceration. The value of MR categorizes melanomas into tumors with low or high proliferative potential, thus giving direct information concerning their capacity to infiltrate deeper layers of the dermis and, potentially, to generate regional lymph node and distant metastases.

\section{Introduction}

Cutaneous malignant melanoma (CMM) is the most deadly form of skin neoplasm. With an estimated mortality of over 55,000 worldwide in 2012 which is increasing yearly and even with a more rapidly growing incidence, CMM has become a major challenge for modern oncology (1). Detailed studies are required to provide accurate risk stratification and to better identify the groups of patients in need of tailored treatment strategies.

In melanomas, multiple factors with potential prognostic value have been described over the years (2-5). Breslow thickness still remains the most powerful prognostic factor and is a substantial component of every CMM pathology report (6). The presence of ulceration has been considered as the second most important primary tumor characteristic for the purpose of predicting patient outcome (5). With the exception of traumatic disruption of the epidermis, ulceration has been a key element in the last two editions of the melanoma TNM staging guidelines of the American Joint Committee on Cancer (AJCC) - its presence verified in microscopic evaluation of changes in the pT stage from pTxa to pTxb $(6,7)$.

Recently, scientific attention has been drawn towards another microscopic feature of the primary tumor, the mitotic rate (MR). The inclusion of this parameter in multivariate models confirmed its significance in risk stratification, particularly in localized melanomas (8-10). Additionally, several studies have indicated that MR has a higher impact than ulceration $(8,11,12)$. As a valuable parameter that reflects tumor proliferative activity and aggressiveness, MR has recently been introduced into the AJCC melanoma staging system (6). Under 
current recommendations, MR is defined as the number of mitotic figures per square millimeter and a value $\geq 1$ upstages the $\mathrm{T}$ subcategory of the pTNM classification from a to $b$, but only at the pT1 level (6). Clinically, this translates into a recommendation for sentinel lymph node biopsy for patients presenting with $\mathrm{pT} 1 \mathrm{~b}$, although not for those with pTla stage tumors (6).

The present study aimed to examine the relationship between key melanoma prognosticators, namely the presence of ulceration and mitotic rate against clinicopathological characteristics and patient survival, and to discuss the results in the context of AJCC melanoma staging recommendations.

\section{Materials and methods}

Patients. The study group consisted of 104 patients with CMM, who were diagnosed between 2005 and 2010 and treated at the Lower Silesian Oncology Center in Wrocław, Poland. The group was selected on the basis of tissue material (paraffin blocks and histopathology slides) and the availability of medical documentation. Comprehensive clinical data were obtained from archival medical records. The diagnostic and therapeutic procedures utilized were determined from medical records in the Oncology Outpatient Clinic of the Lower Silesian Oncology Center and data provided by the Lower Silesian Cancer Registry and Civil Register Office. The study was approved by the Institutional Review Board of the Wrocław Medical University, Poland.

The clinicopathological profile of the patients included the following parameters: age and gender, primary tumor location, tumor stratification according to AJCC, presence or absence of nodal ( $\mathrm{pT}$ or $\mathrm{pN})$ and distant $(\mathrm{pM})$ metastases, information on disease recurrence and sentinel lymph node biopsy (SLNB) procedures (Table I).

Tumor samples and histopathological evaluation. Tumor specimens were fixed in $10 \%$ buffered formalin and embedded in paraffin. All haematoxylin and eosin (H\&E) stained sections were examined by two pathologists. The parameters of the primary tumor recorded in pathology reports included Breslow thickness, Clark level, growth phase, histologic type, mitotic rate (number of mitotic figures per $1 \mathrm{~mm}^{2}$ ), presence of ulceration, lymphangioinvasion, microsatellitosis, intensity of lymphocytic inflammatory infiltrate (TILs, tumor-infiltrating lymphocytes) and microscopic evidence of regression (Table II).

Statistical analysis. Statistical analysis was performed using the Statistica 10.0 and IBM SPSS 21 software packages. Overall survival (OS) was defined as the time between the primary surgical treatment and death, and OS was censored at last follow-up for patients who were still alive. Disease-free survival (DFS) was defined as the time between the primary surgical treatment and the date of relapse. DFS was censored at the last follow-up for patients who survived without disease recurrence or at the date of non-cancer-associated death. Cancer-specific overall survival (CSOS) was defined as the time between the primary surgical treatment and cancerassociated death, and was censored at the last follow-up for surviving patients.
A $\chi^{2}$ test, exact Fisher's test in the case of $2 \times 2$ tables and Spearman's rank correlation were used to analyze the associations between mitotic rate and the presence of ulceration and clinicopathological parameters. Differences between the means were tested with a nonparametric test (Mann-Whitney $\mathrm{U}$ test and Kruskal-Wallis test); the log-rank test was used to compare survival in two groups. The overall survival rate was estimated by the Kaplan-Meier method and the influence of explanatory variables on death risk was analyzed by means of the Cox proportional hazard regression. A P-value $<0.05$ was considered to indicate a statistically significant difference.

\section{Results}

MR and the presence of ulceration in 104 melanoma patients. The mitotic activity of the primary tumors was divided into three categories: no mitotic activity $\left(0 \mathrm{mitoses} / \mathrm{mm}^{2}\right)$, low activity (1-2 mitoses $/ \mathrm{mm}^{2}$ ) and high mitotic rate (hMR; $\geq 3$ mitoses $/ \mathrm{mm}^{2}$ ) (Fig. 1A-D). No mitotic activity was detected in 45 patients $(43.3 \%)$, whereas low MR was observed in 26 patients $(25 \%)$. High proliferative activity was observed in 33 patients (31.7\% of the study group). Analysis of MR in melanomas of various degrees of clinical advancement with regard to pT stage of the primary tumor revealed that only a small percentage of early (pT1 and pT2) tumors exhibited hMR (6 and 10\%, respectively). In the advanced disease, hMR tumors accounted for 48 and 70\%, respectively in T3 and T4 melanomas (Table I).

Ulceration was observed in $49 \%$ of the tumors (Fig. 2A-D). Within the pT1 group of tumors, only a small number $(6 \%)$ of tissue specimens showed microscopic evidence of ulceration. Interestingly, 30\% of pT2 melanomas were ulcerated. Advanced (pT3 and pT4) tumors were characterized by a significantly higher prevalence of ulceration (74 and $91 \%$, respectively) (Table I).

Correlations between $h M R$ and clinicopathological parameters. A high mitotic rate was significantly correlated with higher advancement of the primary tumor ( $\mathrm{pT} ; \mathrm{P}<0.001)$, the presence of nodal and distant metastases $(\mathrm{P}<0.001$ and $\mathrm{P}=0.034$, respectively), positive status for sentinel lymph node $(\mathrm{P}=0.002)$ and disease recurrence $(\mathrm{P}=0.041)$. Furthermore, hMR was strongly associated with deeper infiltration according to Breslow thickness $(\mathrm{P}<0.001)$ and Clark level $(\mathrm{P}<0.001)$, the presence of ulceration $(\mathrm{P}<0.001)$, lymphangioinvasion $(\mathrm{P}<0.001)$, microsatellitosis $(\mathrm{P}=0.012)$ and histologic type (nodular) of the primary tumor $(\mathrm{P}<0.001)$. Interestingly, hMR was related to a lower intensity of lymphocytic inflammatory infiltrate $(\mathrm{P}=0.01)$. No other significant correlations were found between hMR and the other analyzed clinicopathological parameters, including gender, age, location and growth phase of the primary tumor and microscopic evidence of its regression (Table II).

Correlations between the presence of ulceration and clinicopathological parameters. The presence of ulceration was significantly correlated with higher advancement of the primary tumor $(\mathrm{pT} ; \mathrm{P}<0.001)$ and with the presence of metastases in sentinel lymph nodes $(\mathrm{P}=0.001)$ and regional lymph nodes $(\mathrm{P}<0.001)$. It was further demonstrated that the presence of ulceration was associated with deeper tumor 

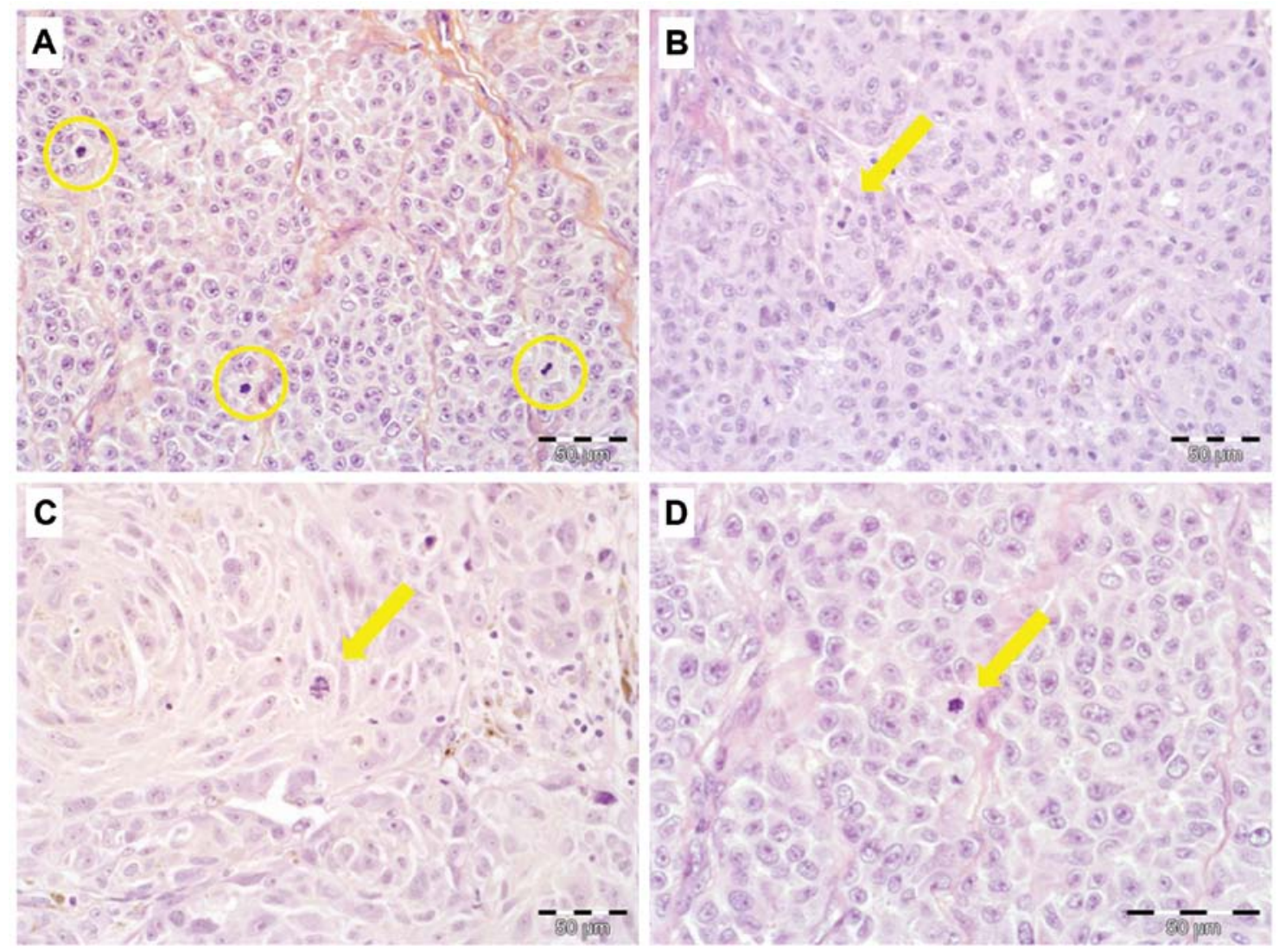

Figure 1. Mitotic activity in cutaneous malignant melanoma. (A) Three pathological mitotic figures (yellow borders) (H\&E staining, magnification x200). (B-D) Single mitotic figure in melanoma (yellow arrows). Magnification: H\&E staining, x200 in B; H\&E staining, x400 in C; H\&E staining, x600 in D.
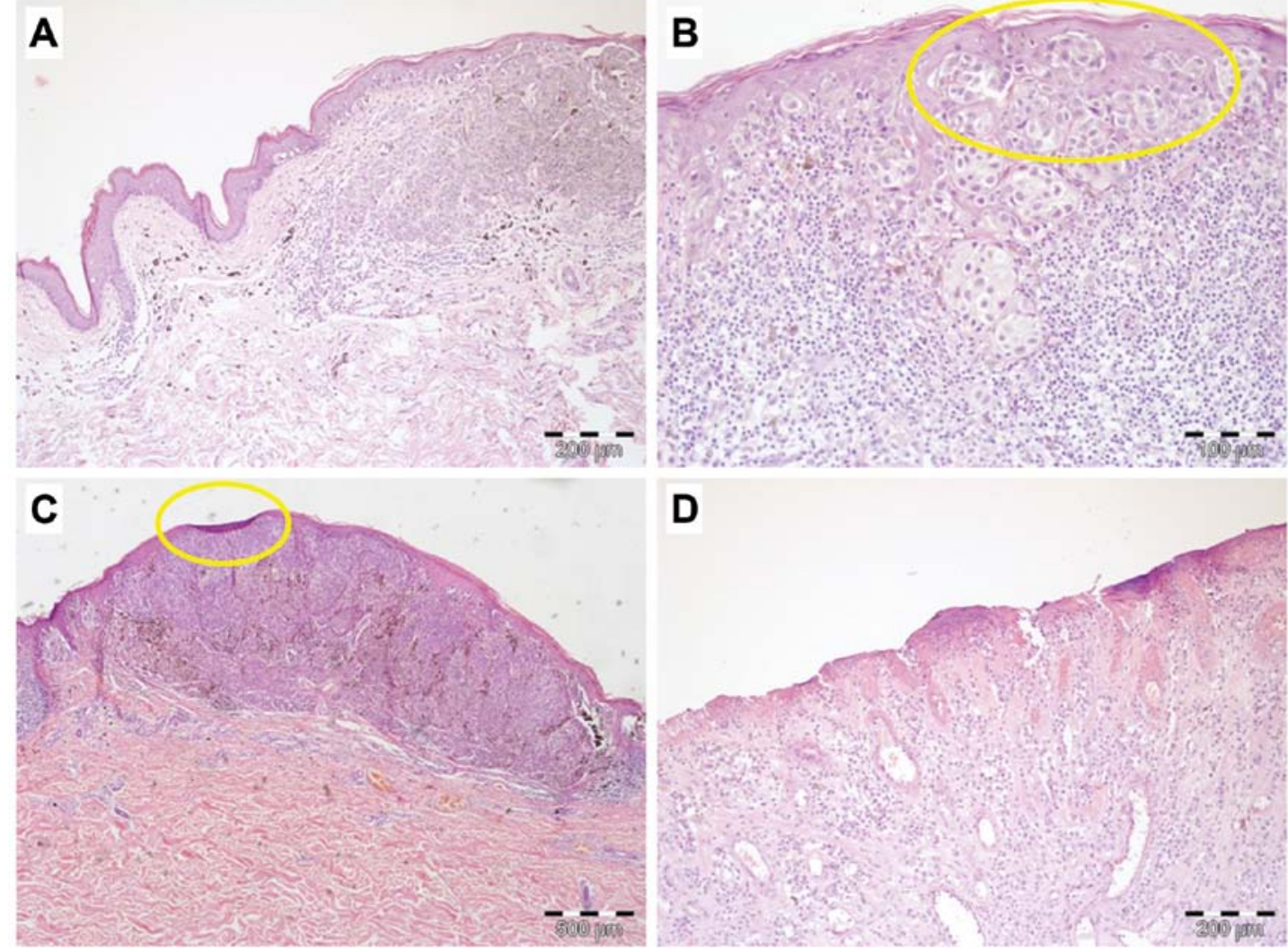

Figure 2. (A) Early superficial spreading malignant melanoma with no evident features of ulceration (H\&E staining, magnification x100). (B) Consumption of epidermis was observed as a potential pre-ulcerated status (H\&E staining, x200). (C) Artifactual wrapping of the epidermis in nodular malignant melanoma which can imitate the presence of focal ulceration (H\&E staining, $x$ 40. (D) Diffuse destruction of the epidermis in advanced melanoma (H\&E staining, x100). 
Table I. Clinicopathological characteristics of the cutaneous malignant melanoma patients.

\begin{tabular}{|c|c|c|c|c|c|}
\hline Clinicopathological characteristics & No $(\%)$ & $\begin{array}{l}\text { High mitotic rate } \\
\qquad\left(\geq 3 / \mathrm{mm}^{2}\right)\end{array}$ & P-value & Ulceration & P-value \\
\hline All patients & $104(100.0)$ & 33 & & 49 & \\
\hline Age (years) & & & 0.598 & & 0.205 \\
\hline Range $\quad(21-79)^{\mathrm{a}}$ & & & & & \\
\hline Mean: $\quad 56.5 \pm 15.4$ & & & & & \\
\hline Median: $\quad 58.5$ & & & & & \\
\hline Gender $^{\mathrm{b}}$ & & & 0.576 & & 0.313 \\
\hline Female & $60(57.7)$ & 19 & & 30 & \\
\hline Male & $44(42.3)$ & 14 & & 19 & \\
\hline Primary tumor location ${ }^{\mathrm{c}}$ & & & 0.494 & & 0.056 \\
\hline Head/neck & $15(14.4)$ & 7 & & 11 & \\
\hline Upper extremities & $18(17.3)$ & 4 & & 8 & \\
\hline Lower extremities & $25(24.0)$ & 7 & & 9 & \\
\hline Trunk & $42(40.4)$ & 13 & & 17 & \\
\hline Hand/foot & $4(3.8)$ & 2 & & 4 & \\
\hline Primary tumor $(\mathrm{pT})^{\mathrm{a}}$ & & & $<0.001$ & & $<0.001$ \\
\hline pT1 & $34(32.7)$ & 2 & & 2 & \\
\hline pT2 & $20(19.2)$ & 2 & & 6 & \\
\hline pT3 & $27(26.0)$ & 13 & & 20 & \\
\hline pT4 & $23(22.1)$ & 16 & & 21 & \\
\hline Sentinel lymph node biopsy status (SNLB) & $60(57.7)$ & & 0.002 & & 0.001 \\
\hline No metastases (SNLB') & $48(80.0)$ & 6 & & 14 & \\
\hline Metastases present $\left(\mathrm{SNLB}^{+}\right)$ & $12(20.0)$ & 7 & & 10 & \\
\hline Regional lymph nodes status $(\mathrm{pN})^{\mathrm{b}}$ & & & $<0.001$ & & $<0.001$ \\
\hline No metastases $\left(\mathrm{pN}^{-}\right)$ & $86(82.7)$ & 20 & & 33 & \\
\hline Metastases present $\left(\mathrm{pN}^{+}\right)$ & $18(17.3)$ & 13 & & 16 & \\
\hline Recurrence $^{b}$ & & & 0.041 & & 0.093 \\
\hline No & $87(83.7)$ & 24 & & 38 & \\
\hline Yes & $17(16.3)$ & 9 & & 11 & \\
\hline Distant metastases $^{\mathrm{b}}$ & & & 0.034 & & 0.147 \\
\hline No & 99 (95.2) & 29 & & 45 & \\
\hline Yes & $5(4.8)$ & 4 & & 4 & \\
\hline
\end{tabular}

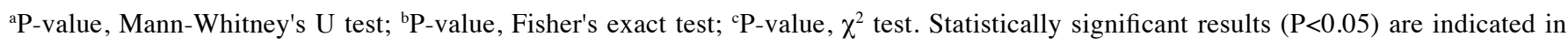
bold font.

infiltration according to Breslow thickness $(\mathrm{P}<0.001)$ and Clark level $(\mathrm{P}<0.001)$, hMR $(\mathrm{P}<0.001)$, lymphangionvasion $(\mathrm{P}<0.001)$ and histologic type (nodular and acral-lentiginous) of the primary tumor $(\mathrm{P}<0.001)$. Another relationship was revealed between a decrease in lymphocytic inflammatory infiltrate intensity and ulceration of the primary tumor $(\mathrm{P}<0.001)$. No further correlations were found regarding the presence of ulceration and other analyzed clinicopathological characteristics (Table II).

Impact of a high mitotic rate and ulceration on the 5-year survival in melanoma patients. In the entire group of 104 patients, hMR was a highly negative prognostic factor, and indicated considerably shorter OS, CSOS and DFS $(\mathrm{P}=0.002$, $\mathrm{P}=0.004$ and $\mathrm{P}<0.001$, respectively) (Fig. 3A, C and E). Similar relationships were observed for ulceration, which also acted as a negative prognosticator for the entire study population ( $\mathrm{P}=0.001$ for $\mathrm{OS}, \mathrm{P}=0.003$ for $\mathrm{CSOS}$ and $\mathrm{P}=0.003$ for $\mathrm{DFS}$ ) (Fig. 3B, D and F).

An important aspect of this study was to analyze the prognostic significance of $\mathrm{hMR}$ and the presence of ulceration in particular pT stages of primary tumor advancement. Notably, hMR appeared to have a statistically significant negative impact on survival in early melanomas in the pT1 $(\mathrm{P}=0.001)$ and pT2 subgroups $(\mathrm{P}=0.006)$ (Fig. 4A and B). Kaplan-Meier analysis of the remaining subsets (pT3 and pT4) did not reveal 
Table II. Correlations between high mitotic rate (hMR) and the presence of ulceration and histopathological characteristics of the cutaneous malignant melanoma primary tumors.

\begin{tabular}{|c|c|c|c|c|c|}
\hline Histopathological characteristics & No. $(\%)$ & $\begin{array}{l}\text { High mitotic rate } \\
\qquad\left(\geq 3 / \mathrm{mm}^{2}\right)\end{array}$ & P-value & Ulceration & P-value \\
\hline Breslow thickness $^{\text {a }}$ & & & $<0.001$ & & $<0.001$ \\
\hline$<1 \mathrm{~mm}$ & $34(32.7)$ & 2 & & 2 & \\
\hline $1.01-2.00 \mathrm{~mm}$ & $20(19.2)$ & 2 & & 5 & \\
\hline $2.01-4.00 \mathrm{~mm}$ & $27(26.0)$ & 16 & & 21 & \\
\hline$>4 \mathrm{~mm}$ & $23(22.1)$ & 13 & & 21 & \\
\hline Clark level $^{\mathrm{a}}$ & & & $<0.001$ & & $<0.001$ \\
\hline $\mathrm{I}$ & $0(0.0)$ & 0 & & 0 & \\
\hline II & $18(17.3)$ & 1 & & 0 & \\
\hline III & $49(47.1)$ & 10 & & 17 & \\
\hline IV & $26(25.0)$ & 15 & & 22 & \\
\hline $\mathrm{V}$ & $11(10.6)$ & 7 & & 10 & \\
\hline Histologic type $e^{b}$ & & & $<0.001$ & & $<0.001$ \\
\hline Superficial spreading melanoma (SSM) & $68(65.4)$ & 11 & & 18 & \\
\hline Nodular malignant melanoma (NMM) & $32(30.8)$ & 20 & & 27 & \\
\hline Acral-lentiginous melanoma (ALM) & $4(3.8)$ & 2 & & 4 & \\
\hline Mitotic rate ${ }^{\mathrm{a}}$ & & & & & $<0.001$ \\
\hline 0 & $45(43.3)$ & & & 4 & \\
\hline $1-2$ & $26(25.0)$ & & & 16 & \\
\hline$\geq 3$ & $33(31.7)$ & & & 29 & \\
\hline Ulceration $^{\mathrm{c}}$ & & & $<0.001$ & & \\
\hline No & $55(52.9)$ & 4 & & & \\
\hline Yes & $49(47.1)$ & 29 & & & \\
\hline Lymphangioinvasion $^{\mathrm{c}}$ & & & $<0.001$ & & $<0.001$ \\
\hline No & $74(71.2)$ & 11 & & 25 & \\
\hline Yes & $30(28.8)$ & 22 & & 24 & \\
\hline Growth phase ${ }^{\mathrm{c}}$ & & & 0.314 & & 0.144 \\
\hline Radial & $3(2.9)$ & 0 & & 0 & \\
\hline Vertical & $101(97.1)$ & 33 & & 49 & \\
\hline Tumor-infiltrating lymphocytes (TILs) ${ }^{\mathrm{b}}$ & & & 0.010 & & $<0.001$ \\
\hline No & $18(17.3)$ & 10 & & 13 & \\
\hline Nonbrisk & $34(32.7)$ & 13 & & 22 & \\
\hline Brisk & $52(50)$ & 10 & & 14 & \\
\hline Microsatellitosis ${ }^{\mathrm{c}}$ & & & 0.012 & & 0.078 \\
\hline No & $98(94.2)$ & 28 & & 44 & \\
\hline Yes & $6(5.8)$ & 5 & & 5 & \\
\hline Tumor regression $^{\mathrm{c}}$ & & & 0.495 & & 0.295 \\
\hline No & $96(92.3)$ & 30 & & 44 & \\
\hline Yes & $8(7.7)$ & 3 & & 5 & \\
\hline
\end{tabular}

${ }^{\text {ap}} \mathrm{P}$-value, Mann-Whitney's U-test; ${ }^{\text {b}} \mathrm{P}$-value, $\chi^{2}$ test; ${ }^{\mathrm{C}} \mathrm{P}$-value, Fisher's exact test. Statistically significant results $(\mathrm{P}<0.05)$ are indicated in bold font.

any important differences in 5-year survival with regard to MR values (Fig. 4C and D).

The presence of ulceration also had a prognostic significance for early melanomas, but only for pT1 tumors $(\mathrm{P}=0.05)$ (Fig. 5A). Kaplan-Meier analysis of the other groups (pT2-T4) did not show any influence of ulceration on the 5-year survival (Fig. 5B-D).

Multivariable Cox regression analysis. Multivariate analysis confirmed that a high mitotic rate and the presence of distant 

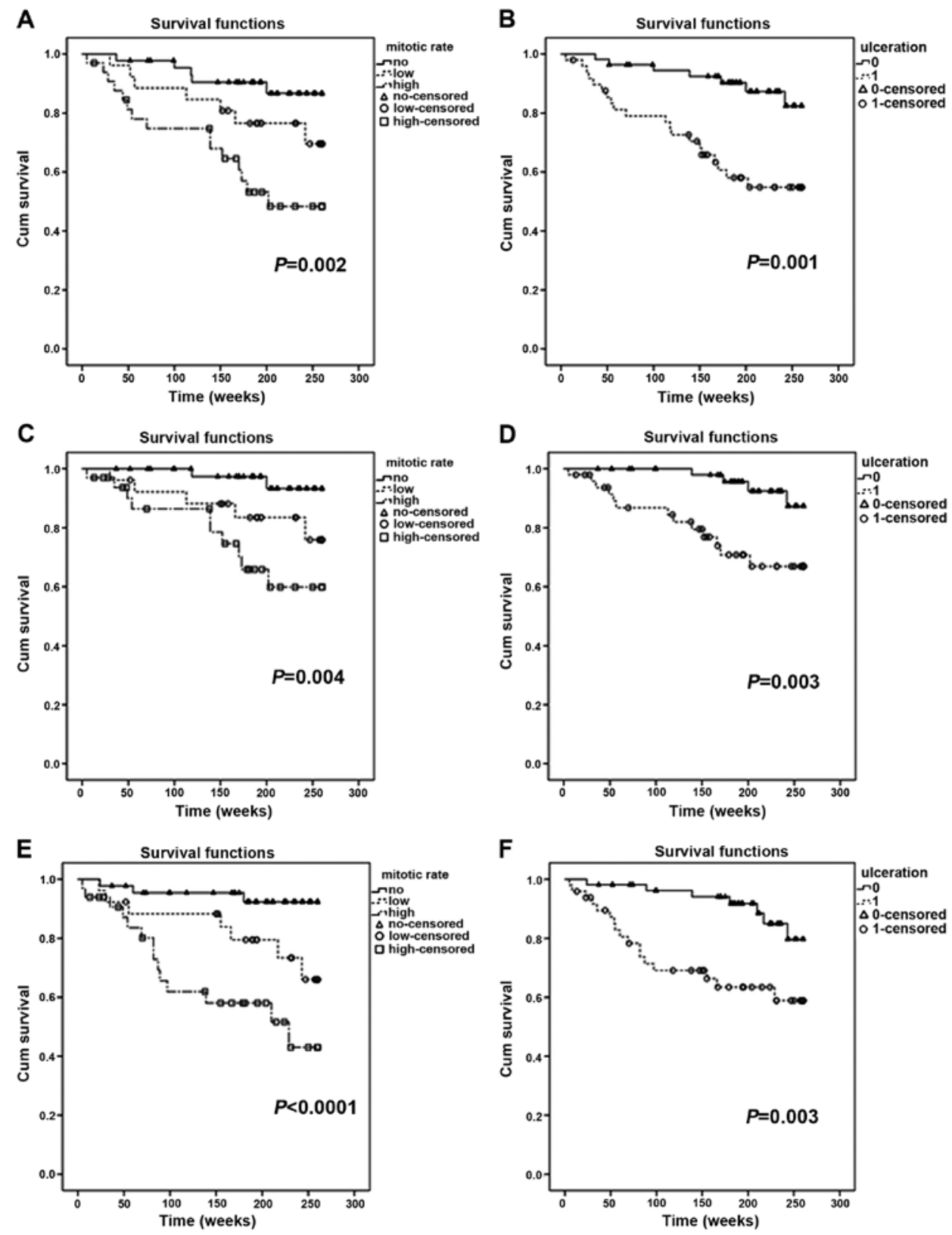

Figure 3. Impact of a high mitotic rate and the presence of ulceration on 5-year survival in melanoma patients in the entire study group of 104 patients (Kaplan-Meier curves). hMR was a highly negative prognostic factor indicating considerably shorter (A) overall survival, (C) cancer-specific overall survival and (E) disease-free survival. Similar relationships were observed for ulceration, which also served as a negative prognosticator for the entire study group in terms of significantly shorter (B) overall survival, (D) cancer-specific overall survival and (F) disease-free survival.

metastases were strongly associated with an unfavorable prognosis (hMR: $\mathrm{P}=0.005$; HR, 1.247; 95\% CI, 1.069-1.456; pM: $\mathrm{P}=0.001$; HR, 5.071; 95\% CI, 1.883-13.656). Ulceration had no prognostic significance in the Cox proportional hazards model.

\section{Discussion}

The aim of the present study was to investigate the relevance of the mitotic rate and primary tumor ulceration for the prognosis of CMM, as well as correlations with other clinicopathological features. In our study group of 104 patients, hMR and the presence of ulceration were highly negative prognostic factors, strongly correlated with shorter overall and cancer- specific overall survival. An important aspect of the study was to analyze the prognostic significance of hMR and the presence of ulceration in particular $\mathrm{pT}$ stages of primary tumor advancement. Notably, hMR appeared to have a statistically significant negative impact on survival in early melanomas in the $\mathrm{pT} 1(\mathrm{P}=0.001)$ and $\mathrm{pT} 2$ subgroups $(\mathrm{P}=0.006)$, whereas Kaplan-Meier analysis for pT3 and pT4 tumors did not reveal any important differences in 5-year survival with regard to MR values. The presence of ulceration also had a prognostic significance, but only for pT1 melanomas ( $\mathrm{P}=0.05)$. Kaplan-Meier analysis of other groups (pT2-T4) did not show any influence of ulceration on 5-year survival.

The negative effect of elevated MR on patient survival has been addressed in numerous studies and currently, this 

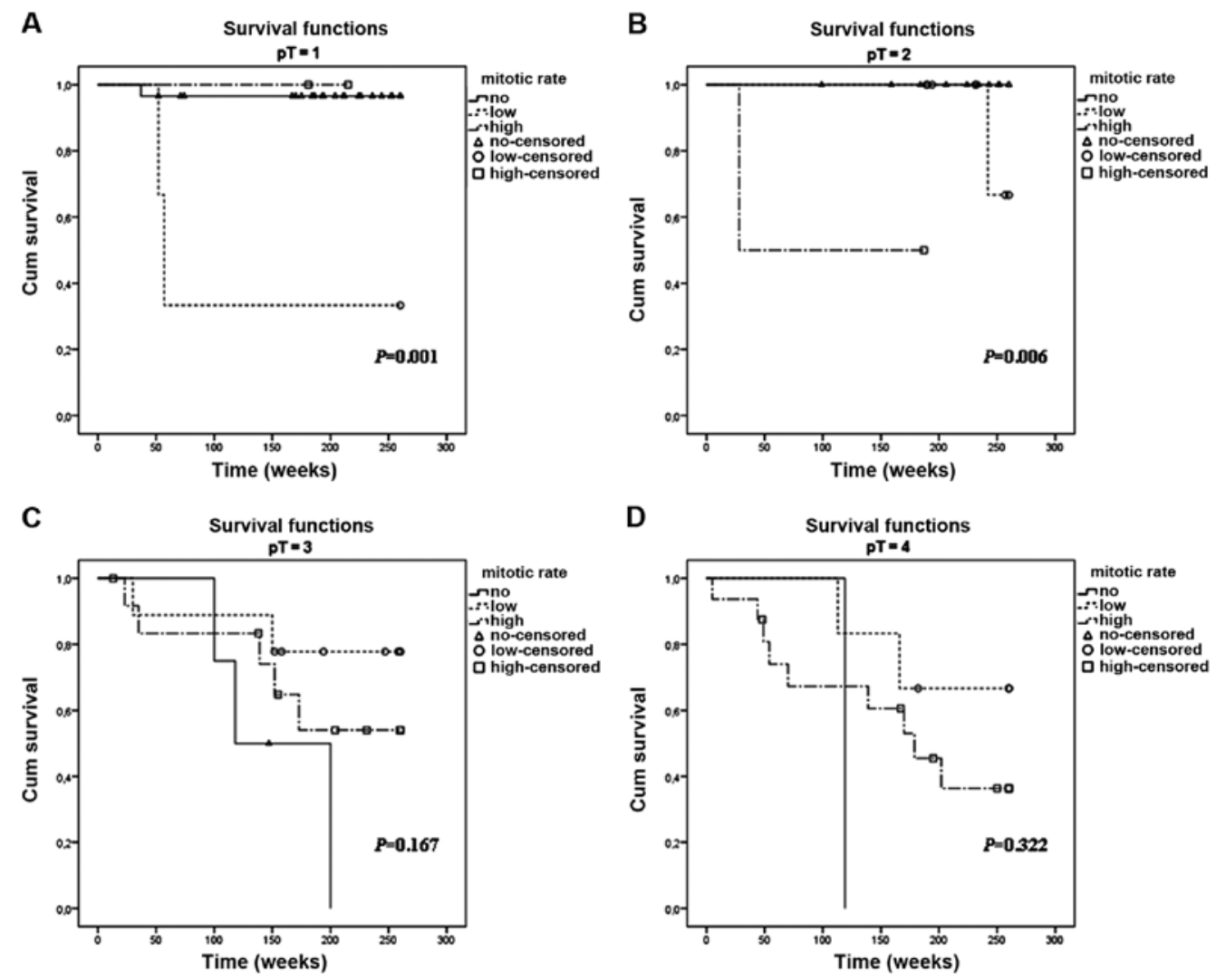

Figure 4. Kaplan-Meier analysis of the prognostic significance of hMR in particular pT stages of the primary tumor advancement. Notably, hMR appeared to have a statistically significant negative impact on survival in early melanomas in both (A) pT1 and (B) pT2 subgroups. (C and D) Kaplan-Meier analysis of the remaining subsets (pT3 and pT4) did not reveal any important differences in 5-year survival with regard to values of MR.

A

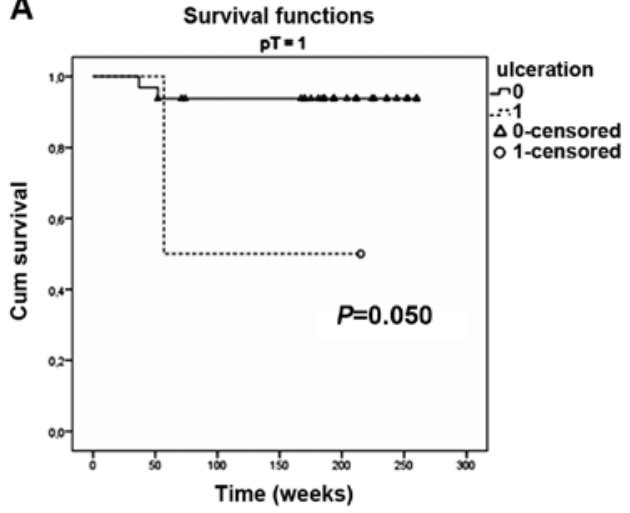

C

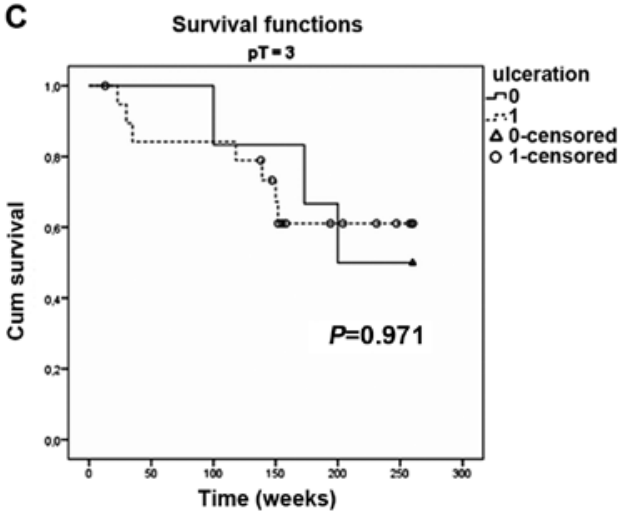

B

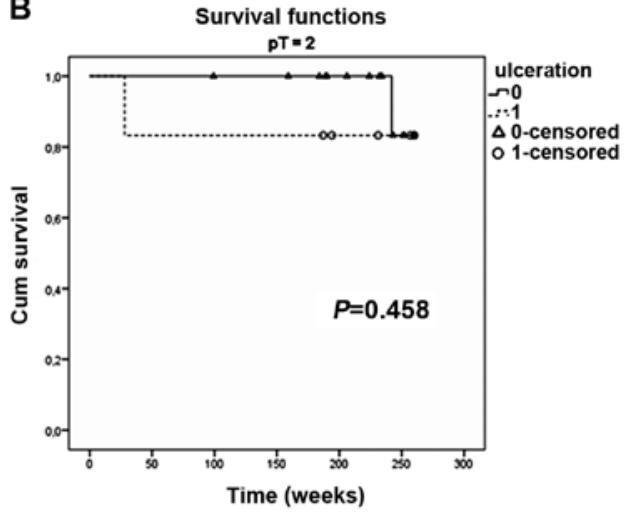

D

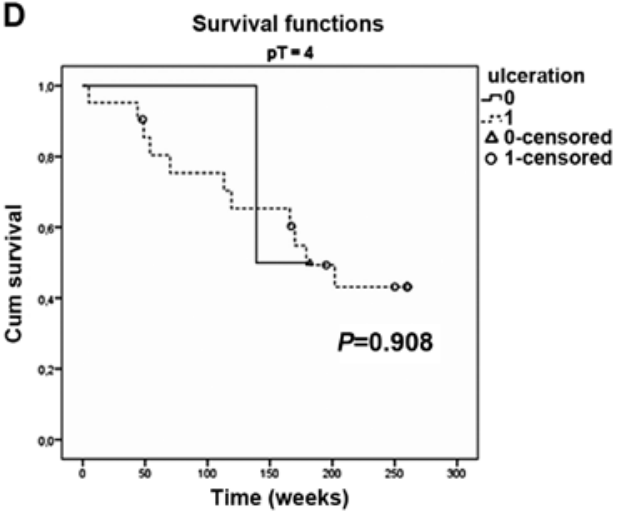

Figure 5. Kaplan-Meier analysis of the prognostic significance of the ulceration in various pT stages of the primary tumor advancement. (A) The presence of ulceration also had prognostic significance for early melanomas, but only in pT1 tumors. (B-D) Kaplan-Meier analysis of other groups (pT2-T4) did not show any influence of ulceration on 5-year survival. 
parameter, albeit in a very limited way, affects the TNM staging of CMM $(6,8,10-14)$. However, there are other examples in the literature indicating a far greater significance of MR than that provided by the current version of AJCC recommendations. In the study of Zettersten et al increased MR negatively impacted overall survival in a population of patients with thick $(>4 \mathrm{~mm})$ CMM (15). Nagore et al demonstrated that in 823 localized invasive tumors, MR was the most important prognostic factor of disease-free survival in a multivariable analysis when Breslow thickness was considered as a continuous variable (16).

Considering our results, the mitotic rate emerged as a powerful parameter providing information on patient survival, and on other crucial clinicopathological features. Thus hMR is related to more advanced metastatic cancers and to greater risk of disease recurrence. The relationship between hMR and distant metastases has been recently reported by Murali et al (17). Moreover, our study confirms an association between hMR and positivity of SNLB, which supports the validity of the AJCC recommendation to upstage from pTla to pTlb based on increased MR $(8,9,14)$. An inverse correlation between MR and TIL grade has been noted by Azimi et al (18), but refuted by others (16).

Another aspect of our study was the analysis of the prognostic significance of ulceration and investigation of correlations between ulceration status and other clinicopathological parameters. There are examples in the literature which demonstrate that the impact of ulceration on melanoma pathology is unclear. Meanwhile, according to some studies, ulceration loses its role as an independent adverse prognostic factor when MR is included in multivariable models $(12,17,19)$. Eigentler et al reported that the presence or absence of ulceration does not influence survival in multivariable analyses of putative CMM prognostic factors among $\mathrm{pT} 1$ and $\mathrm{pT} 4$ tumors, while it remains significant in intermediate (pT2 and $\mathrm{pT} 3$ ) melanomas. However, MR was not considered in this study (20). It should be said here that determining a universal and coherent definition of tumor-derived (and only tumor-derived) ulceration is another problem, resulting in inter-observer reproducibility that is not entirely satisfactory (21).

In regards to the other correlations observed between ulceration and clinicopathological characteristics, our data are generally concordant with other reports. Whereas no differences relating to the presence of ulceration were found in regards to gender, age and primary tumor location, the findings support the broad consensus that ulcerated lesions are thicker and more deeply invasive $(5,22,23)$. An association between ulcerated melanomas and nodular histologic type has also been previously observed (22). In accordance with our results, the presence of ulceration has been postulated as a predictor of sentinel lymph node involvement $(14,24)$. An interesting aspect reported by Balch $e t a l$ and confirmed by our study is the relationship between scanty lymphocytic infiltrate and the presence of ulceration (25).

Considering the biology of melanoma, MR seems to be a more reliable parameter than the presence or otherwise of ulceration. The value of MR categorizes melanomas into tumors with low or high proliferative potential, thus giving direct information concerning their capacity to infiltrate deeper layers of the dermis and, potentially, to generate regional lymph node and distant metastases. MR is a much more objective parameter than ulceration and its origin is never artifactual. Instead, it always reflects the true biology of the tumor, independently of the infiltration depth and extent of epidermal disruption. In the authors' opinion, ulceration is a valuable parameter that mirrors the invasive potential of melanoma cells, albeit, primarily in moderately advanced (pT1 and pT2) tumors. In these cases, the etiopathogenesis of ulceration, strictly related to the destructive influence of neoplastic melanocytes (so called consumption of the epidermis), is doubtlessly cancer related.

In more deeply infiltrating (pT3, pT4) tumors, ulceration loses its role as an objective parameter associated with the nature of melanoma cells and reflecting their aggressive behavior. In advanced melanomas, the ulceration may be etiologically unrelated to epidermal consumption by cancer cells and may be only a morphological manifestation of a purely mechanical external injury. Although an analogous situation may also occur in non-advanced tumors, it is much less probable.

To sum up, both hMR and ulceration have a very significant influence on the outcome of patients with cutaneous melanoma. However, as stressed above, it is hMR that is a much more objective parameter, more accurately reflecting the biology of a particular tumor. Because of our relatively small study population, further larger-scale investigations are needed to more precisely determine the pathophysiological role and prognostic significance of hMR and ulceration, particularly in patients with early melanoma, in whom more intensive therapy and/or more extensive post-operative followup may be justified in order to improve the prognosis.

\section{Acknowledgements}

This study was supported by Wroclaw Medical University research grant Pbmn108.

\section{References}

1. Ferlay J, Soerjomataram I, Ervik M, Dikshit R, Eser S, Mathers C, Rebelo M, Parkin DM, Forman D and Bray F (eds): GLOBOCAN 2012 Cancer Incidence and Mortality Worldwide. IARC CancerBase V1.0, No. 11. International Agency for Research on Cancer, Lyon, 2013.

2. Clark WH Jr, From L, Bernardino EA and Mihm MC: The histogenesis and biologic behavior of primary human malignant melanomas of the skin. Cancer Res 29: 705-727, 1969.

3. Breslow A: Thickness, cross-sectional areas and depth of invasion in the prognosis of cutaneous melanoma. Ann Surg 172: 902-908, 1970.

4. Balch CM, Murad TM, Soong SJ, Ingalls AL, Halpern NB and Maddox WA: A multifactorial analysis of melanoma: prognostic histopathological features comparing Clark's and Breslow's staging methods. Ann Surg 188: 732-742, 1978.

5. Balch CM, Soong SJ, Gershenwald JE, Thompson JF, Reintgen DS, Cascinelli N, Urist M, McMasters KM, Ross MI, Kirkwood JM, Atkins MB, Thompson JA, Coit DG, Byrd D, Desmond R, Zhang Y, Liu PY, Lyman GH and Morabito A: Prognostic factors analysis of 17,600 melanoma patients: validation of the American Joint Committee on Cancer melanoma staging system. J Clin Oncol 19: 3622-3634, 2001.

6. Balch CM, Gershenwald JE, Soong SJ, Thompson JF, Atkins MB, Byrd DR, Buzaid AC, Cochran AJ, Coit DG, Ding S, Eggermont AM, Flaherty KT, Gimotty PA, Kirkwood JM, McMasters KM, Mihm MC Jr, Morton DL, Ross MI, Sober AJ and Sondak VK: Final version of 2009 AJCC melanoma staging and classification. J Clin Oncol 27: 6199-6206, 2009. 
7. Balch CM, Buzaid AC, Soong SJ, Atkins MB, Cascinelli N, Coit DG, Fleming ID, Gershenwald JE, Houghton A Jr, Kirkwood JM, McMasters KM, Mihm MF, Morton DL, Reintgen DS, Ross MI, Sober A, Thompson JA and Thompson JF: Final version of the American Joint Committee on Cancer staging system for cutaneous melanoma. J Clin Oncol 19: 3635-3648, 2001.

8. Thompson JF, Soong SJ, Balch CM, Gershenwald JE, Ding S, Coit DG, Flaherty KT, Gimotty PA, Johnson T, Johnson MM, Leong SP, Ross MI, Byrd DR, Cascinelli N, Cochran AJ Eggermont AM, McMasters KM, Mihm MC Jr, Morton DL and Sondak VK: Prognostic significance of mitotic rate in localized primary cutaneous melanoma: an analysis of patients in the multi-institutional American Joint Committee on Cancer melanoma staging database. J Clin Oncol 29: 2199-2205, 2011.

9. Kesmodel SB, Karakousis GC, Botbyl JD, Canter RJ, Lewis RT, Wahl PM, Terhune KP, Alavi A, Elder DE, Ming ME, Guerry D, Gimotty PA, Fraker DL, Czerniecki BJ, and Spitz FR: Mitotic rate as a predictor of sentinel lymph node positivity in patients with thin melanomas. Ann Surg Oncol 12: 449-458, 2005.

10. Balch CM, Gershenwald JE, Soong SJ, Thompson JF, Ding S, Byrd DR, Cascinelli N, Cochran AJ, Coit DG, Eggermont AM, Johnson T, Kirkwood JM, Leong SP, McMasters KM, Mihm MC Jr, Morton DL, Ross MI and Sondak VK: Multivariate analysis of prognostic factors among 2,313 patients with stage III melanoma: comparison of nodal micrometastases versus macrometastases. J Clin Oncol 28: 2452-2459, 2010.

11. Azzola MF, Shaw HM, Thompson JF, Soong SJ, Scolyer RA, Watson GF, Colman MH and Zhang Y: Tumor mitotic rate is a more powerful prognostic indicator than ulceration in patients with primary cutaneous melanoma: an analysis of 3661 patients from a single center. Cancer 97: 1488-1498, 2003.

12. Barnhill RL, Katzen J, Spatz A, Fine J and Berwick M: The importance of mitotic rate as a prognostic factor for localized cutaneous melanoma. J Cutan Pathol 32: 268-273, 2005.

13. Francken AB, Shaw HM, Thompson JF, Soong SJ, Accortt NA, Azzola MF, Scolyer RA, Milton GW, McCarthy WH, Colman MH and McGovern VJ: The prognostic importance of tumor mitotic rate confirmed in 1317 patients with primary cutaneous melanoma and long follow-up. Ann Surg Oncol 11: 426-433, 2004.

14. Spatz A, Stock N, Batist G and van Kempen LC: The biology of melanoma prognostic factors. Discov Med 10: 87-93, 2010

15. Zettersten E, Sagebiel RW, Miller JR III, Tallapureddy S, Leong SP and Kashani-Sabet M: Prognostic factors in patients with thick cutaneous melanoma (>4 mm). Cancer 94: 1049-1056, 2002.
16. Nagore E, Oliver V, Botella-Estrada R, Moreno-Picot S, Insa A, and Fortea JM: Prognostic factors in localized invasive cutaneous melanoma: high value of mitotic rate, vascular invasion and microscopic satellitosis. Melanoma Res 15: 169-177, 2005.

17. Murali R, Haydu LE, Long GV, Quinn MJ, Saw RP, Shannon K, Spillane AJ, Stretch JR, Kefford RF, Thompson JF and Scolyer RA: Clinical and pathologic factors associated with distant metastasis and survival in patients with thin primary cutaneous melanoma. Ann Surg Oncol 19: 1782-1789, 2012.

18. Azimi F, Scolyer RA, Rumcheva P, Moncrieff M, Murali R, McCarthy SW, Saw RP and Thompson JF: Tumor-infiltrating lymphocyte grade is an independent predictor of sentinel lymph node status and survival in patients with cutaneous melanoma. J Clin Oncol 30: 2678-2683, 2012.

19. Han D, Zager JS, Shyr Y, Chen H, Berry LD, Iyengar S, Djulbegovic M, Weber JL, Marzban SS, Sondak VK, Messina JL, Vetto JT, White RL, Pockaj B, Mozzillo N, Charney KJ, Avisar E, Krouse R, Kashani-Sabet M and Leong SP: Clinicopathologic predictors of sentinel lymph node metastasis in thin melanoma. J Clin Oncol 31: 4387-4393, 2013.

20. Eigentler TK, Buettner PG, Leiter U and Garbe C: Impact of ulceration in stages I to III cutaneous melanoma as staged by the American Joint Committee on Cancer Staging System: an analysis of the German Central Malignant Melanoma Registry. J Clin Oncol 22: 4376-4383, 2004

21. Spatz A, Cook MG, Elder DE, Piepkorn M, Ruiter DJ and Barnhill RL: Interobserver reproducibility of ulceration assessment in primary cutaneous melanomas. Eur J Cancer 39: 1861-1865, 2003.

22. Taylor RC, Patel A, Panageas KS, Busam KJ and Brady MS: Tumor-infiltrating lymphocytes predict sentinel lymph node positivity in patients with cutaneous melanoma. J Clin Oncol 25: 869-875, 2007.

23. Ostmeier H, Fuchs B, Otto F, Mawick R, Lippold A, Krieg V and Suter L: Can immunohistochemical markers and mitotic rate improve prognostic precision in patients with primary melanoma? Cancer 85: 2391-2399, 1999.

24. Niakosari F, Kahn HJ, McCready D, Ghazarian D, Rotstein LE, Marks A, Kiss A and From L: Lymphatic invasion identified by monoclonal antibody D2-40, younger age, and ulceration: predictors of sentinel lymph node involvement in primary cutaneous melanoma. Arch Dermatol 144: 462-467, 2008.

25. Balch CM, Wilkerson JA, Murad TM, Soong SJ, Ingalls AL and Maddox WA: The prognostic significance of ulceration of cutaneous melanoma. Cancer 45: 3012-3017, 1980. 